\title{
Maxillary Intermolar Width Of Pakistanis With Untreated Normal Occlusion
}

\author{
Muhammad Azeem, Arfan ul Haq, Javed Iqbal, Asif Iqbal, Waheed ul Hamid
}

\section{ABSTRACT:}

Objective: Intermolar width is a key measurement which assists in treatment planning of orthodontic patients requiring expansion as an alternate to premolar extraction. The present research was aimed at determining the mean value of intermolar arch width (IMW) of untreated normal arch Pakistani patients visiting tertiary care dental hospital

Material \& Methods: This cross sectional study was carried out using IMW measurements on plaster model of 120 untreated normal occlusion patients, at Department of Orthodontics, Faisalabad Medical University and de'Montmorency College of dentistry, from 15-12-2016 to 15-10-2017. The non probability consecutive sampling technique was used in this study. Data analysis was done using SPSS software 21.0.0.

Results: The mean age of the subjects was $18.23 \pm 3.75$ years. The mean value of IMW in selected subjects was $45.33 \pm 3.42$ mm.

Conclusion: Study results concluded that in Pakistanis, ideally align maxillary arch and occlusion can be achieved with upper intermolar distances of $45.33 \pm 3.42 \mathrm{~mm}$

Keywords: Intermolar; Dental arch width; Occlusion.

\section{INTRODUCTION:}

In determining the normal dental arch width of a population, intermolar width (IMW) is a key measurement which assists in diagnosis and treatment planning of orthodontic patients, especially in patients requiring expansion as an alternate to premolar extractions in a patient having narrow dental $\operatorname{arches}^{1-3}$. Dental arch importance in orthodontic diagnosis, treatment planning and post treatment stability is well understood.

Numerous dental arch indices have been proposed, such as, Pont and Schwarz proposed numerical indices. Howe concluded that ideal IMW are $37.4 \mathrm{~mm}$ in boys and 36.2 $\mathrm{mm}$ in girls. However all indices gave poor estimation of maxillary arch width. For index validity, actual upper arch width should be as close as possible to predicted arch widths, in normal occlusion subjects.

There exist certain racial differences in terms of norms of

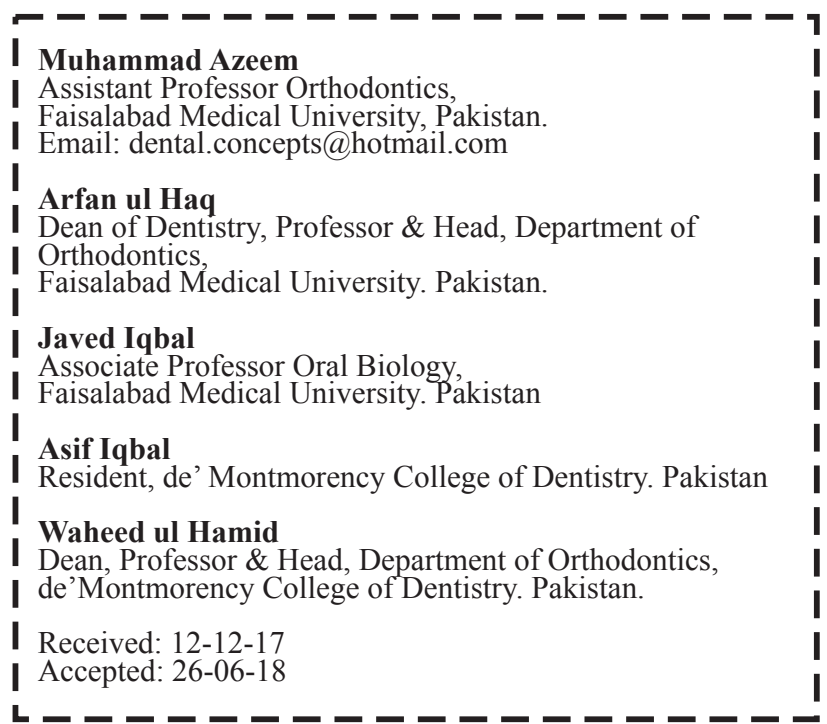

mean IMW width. IMW in Kuwait residents was $51.32 \mathrm{~mm}$ $\pm 2.61^{10}$, in Colombian subjects mean IMW was found to be $45.9 \pm 3.9$, in Karachi population it was $45.6 \mathrm{~mm} \pm 2.3$, and in Nepalese it was $47.94 \pm 3.34$. In general, IMW dimension remains very stable with some degrees of sexual dimorphism present. The findings of one study indicated that maxillary dental arch width measurements were significantly narrower in the Class III group as compared to normal occlusion group $(\mathrm{P}<.001)^{14}$.

This study was designed with aim to measure the mean IMW of subjects visiting Department of Orthodontics, Faisalabad Medical University and de'Montmorency College of dentistry, In orthodontics change of $1 \mathrm{~mm}$ is crucial while treatment planning decisions for extraction verses nonextraction orthodontic cases.

The Objective of current study was to measure the mean dental arch width i.e. IMW in our population.

\section{MATERIAL AND METHODS:}

This cross sectional study was conducted at Faisalabad Medical University and de'Montmorency College of Dentistry, from 15-12-2016 to 15-10-2017. 120 untreated normal occlusion patients was estimated as sample size, using $95 \%$ confidence level, $\mathrm{d}=1$ with an expected IMW = $47.23 \mathrm{~mm} \pm 2.65 .^{10}$ Non probability consecutive sampling was employed. Following are the inclusion criteria:

No history of Ortho-treatment

Untreated normal occlusion patients

12 to 25 year age, both genders

Patient having permanent dentition from 16 to 26

The exclusion criteria are:

Partially erupted posterior teeth

Grossly carious maxillary posterior teeth

Rotations of upper posterior teeth

Incisor irregularity 
After ethical review committee (ERC) approval, sample of 120 untreated normal occlusion patients were included according to inclusion and exclusion parameters. IMW was calculated on plaster models by single investigator, as the distance from upper one side first permanent molar to the same on other side at distobuccal cuspal tip on the occlusal surface, using digital caliper. Ideal occlusion patients were those who got following features ${ }^{10}$ :

Lack of crowding, spaces, cross bite, CO-CR shift, midline discrepancy in anterior or posterior part of either arch

Normal overjet and

Normal overbite

Data analysis was done with SPSS software version 21.0.0. Mean and standard deviation (S.D) was calculated for mean IMW, frequency and percentage for gender. Effect modifiers of age and gender were stratified. Following stratification chi square test was applied. $p$ value $=0.05$ was taken as significant.

\section{RESULTS:}

The mean age of selected sample was $18.23 \pm 3.75$ years. The minimum age of the patient was 12 years while the maximum age was $25.60(50 \%)$ patients were boys and $60(50 \%)$ patients were girls. Overall mean value of IMW was $45.33 \pm 3.42 \mathrm{~mm}$. The minimum IMW in the patient was $40 \mathrm{~mm}$ while the maximum IME was $50 \mathrm{~mm}$ (Chi value $1.92 \mathrm{p}$ - value 0.165 ).

$\leq 20$ years age subjects were 82 , in which $45 \mathrm{~mm}$ IMW was calculated in 46 cases, similarly $>20$ years patients were 38 , in which $45 \mathrm{~mm}$ IMW was found out to be in 7 cases only. There was insignificant differences of IMW for different age and gender groups (Table 1).

\section{DISCUSSION:}

Inter molar width is one of the key calculation for measuring and access the posterior maxillary arch normality ${ }^{15,16}$. As per Moorrees et al. ${ }^{17}$ mandibular IMW usually increased in late mixed dentition and early permanent dentition but remained constant following permanent dentition.

In present research, the mean IMW of selected sample was $45.33 \mathrm{~mm} \pm 3.42$, which is different from the studies conducted elsewhere. In Norwegian sample, mean IMW was found out to be $46.11 \mathrm{~mm}^{18}$. Measured mean IMW in Kuwait

\begin{tabular}{|c|c|c|c|l|}
\hline \multirow{4}{*}{$\begin{array}{c}\text { Inter molar } \\
\text { width }\end{array}$} & & Mean & SD & \\
\cline { 2 - 5 } & $\leq \mathbf{2 0}$ years & 44.83 & 3.22 & t-value -1.26 \\
\cline { 2 - 4 } & $\mathbf{2 0}$ years & 46.42 & 3.65 & p-value 0.127 \\
\cline { 2 - 4 } & Male & 44.37 & 3.53 & t-value -1.70 \\
\cline { 2 - 4 } & Female & 46.30 & 3.06 & p value 0.094 \\
\hline
\end{tabular}

Table 1: Comparison of inter molar width with Age \& Gender population was $51.32 \mathrm{~mm} \pm 2.61$, in Colombian sample mean IMW was $45.9 \pm 3.9$, in a study done in Karachi it was 45.6 $\mathrm{mm} \pm 2.3$, and in Nepalese population it was $47.94 \mathrm{~mm}$ \pm 3.34 . The upper IMW at the distobuccal cusps of the first molars of the Pakistanis were narrower than Chinese and Caucasians ${ }^{19,20,21}$. Comparison of IMW values of current study with different local and international studies is difficult, due to the fact that most of the conducted studies on IMW measurement used different landmarks for measuring the intermolar width.

In present research, IMW values were greater in girls (46.30 $\pm 3.06 \mathrm{~mm}$ ) than in boys $(44.37 \pm 3.53 \mathrm{~mm})$, which is not in agreement with previous studies where IMW values were greater in males than in females ${ }^{11,22-28}$. In present research, there was no statistically significant difference of IMW values for different ages, which is again not in agreement with previous studies ${ }^{17,29-30}$. These differences may be due to the racial, genetic and dietary differences among various populations, as all of these factors play important role in development of arch length width and other dimensions.

Because of the lack of reference data for Pakistanis and the limited validity of existing methods to predict IMW widths, the purpose of this research was to calculate the mean IMW of upper arch in Pakistanis. However further large scale studies are suggested with improved sample size and multicentric approach.

\section{CONCLUSION:}

Study results concluded that in Pakistanis, ideally align maxillary arch and occlusion can be achieved with upper intermolar distances of $45.33 \pm 3.42 \mathrm{~mm}$.

\section{REFERENCES:}

1. Lione R, Buongiorno M, Franchi L, Cozza P. Evaluation of maxillary arch dimensions and palatal morphology in mouthbreathing children by using digital dental casts. International journal of pediatric otorhinolaryngology. 2014;78(1):91-5.

2. McNamara Jr JA, Baccetti T, Franchi L, Herberger TA. Rapid maxillary expansion followed by fixed appliances: a longterm evaluation of changes in arch dimensions. The Angle orthodontist. 2003;73(4):344-53.

3. Ferris T, Alexander R, Boley J, Buschang PH. Long-term stability of combined rapid palatal expansion-lip bumper therapy followed by full fixed appliances. American journal of orthodontics and dentofacial orthopedics. 2005;128(3):31025.

4. Tan WH, Sampson WJ, Townsend GC. A longitudinal study of changes in tooth and dental arch dimensions from the primary to permanent dentitions. Australian Dental Journal. 2014;59(4):S23-4.

5. Thilander B. Dentoalveolar development in subjects with normal occlusion. A longitudinal study between the ages of 5 and 31 years. The European Journal of Orthodontics. 2009;31(2):109-20.

6. Miller CL, Araújo EA, Behrents RG, Oliver DR, Tanaka OM. Mandibular arch dimensions following bonded and banded rapid maxillary expansion. Journal of the World Federation 
of Orthodontists. 2014;3(3):119-23.

7. Pont A. Der zahn-index in der orthodontie. Z Zahnärztl Orthop. 1909;3:306-21.

8. Schwarz AM, Gratzinger M. Removable orthodontic appliances: Saunders; 1966.

9. Howe RP, McNamara JA, O'Connor KA. An examination of dental crowding and its relationship to tooth size and arch dimension. American journal of orthodontics. 1983;83(5):36373.

10. Rastegar-Lari T, Al-Azemi R, Thalib L, Årtun J. Dental arch dimensions of adolescent Kuwaitis with untreated ideal occlusion: Variation and validity of proposed expansion indexes. American journal of orthodontics and dentofacial orthopedics. 2012;142(5):635-44.

11. Alvaran N, Roldan SI, Buschang PH. Maxillary and mandibular arch widths of Colombians. American journal of orthodontics and dentofacial orthopedics. 2009;135(5):649-56.

12. Rathi MK, Fida M. Applicability of Pont's index in orthodontics. J Coll Physicians Surg Pak. 2014;24:256-60.

13. Dhakal J, Shrestha RM, Pyakurel U. Assessment of Validity of Pont's Index and Establishment of Regression Equation to Predict Arch Width in Nepalese Sample. Orthodontic Journal of Nepal. 2014;4(1):12-6.

14. Uysal T, Usumez S, Memili B, Sari Z. Dental and alveolar arch widths in normal occlusion and Class III malocclusion. The Angle orthodontist. 2005;75(5):809-13.

15. Santana L, Motro M, Bamashmous MS, Kantarci A, Will LA. Buccolingual angulation and intermolar width changes in the maxillary first molars of untreated growing children. American Journal of Orthodontics and Dentofacial Orthopedics. 2017;151(5):921-8.

16. Wahaj A, Ahmed I. Comparison of Intercanine and Intermolar Width Between Cleft Lip Palate and Normal Class I Occlusion Group. Journal of the College of Physicians and Surgeons-Pakistan: JCPSP. 2015;25(11):811-4.

17. Moorrees CF, Reed RB. Changes in dental arch dimensions expressed on the basis of tooth eruption as a measure of biologic age. Journal of dental research. 1965;44(1):129-41.

18. Lindsten R, Ögaard B, Larsson E, Bjerklin K. Transverse dental and dental arch depth dimensions in the mixed dentition in a skeletal sample from the 14th to the 19th century and Norwegian children and Norwegian Sami children of today. The Angle orthodontist. 2002;72(5):439-48.
19. Ling JY, Wong RW. Dental arch widths of Southern Chinese. The Angle Orthodontist. 2009;79(1):54-63.

20. Moorrees CF. The Aleut dentition: a correlative study of dental characteristics in an Eskimoid people. Harvard University Press; 1957.

21. Prahl-Andersen B, Kowalski CJ, Heydendael P. A MixedLongitudinal Interdisciplinary Study of Growth and Development. New York, NY: Academic Press; 1979.

22. Knott VB. Longitudinal study of dental arch widths at four stages of dentition. The Angle Orthodontist. 1972;42(4):38794.

23. Sinclair PM, Little RM. Maturation of untreated normal occlusions. American journal of orthodontics. 1983;83(2):11423.

24. Tibana RH, Meira Palagi L, Miguel JA. Changes in dental arch measurements of young adults with normal occlusiona longitudinal study. The Angle orthodontist. 2004;74(5):61823.

25. Thilander B. Dentoalveolar development in subjects with normal occlusion. A longitudinal study between the ages of 5 and 31 years. The European Journal of Orthodontics. 2009;31(2):109-20.

26. Dalidjan M, Sampson W, Townsend G. Prediction of dental arch development: an assessment of Pont's Index in three human populations. American Journal of Orthodontics and Dentofacial Orthopedics. 1995;107(5):465-75.

27. Al-Omari IK, Duaibis RB, Al-Bitar ZB. Application of Pont's Index to a Jordanian population. The European Journal of Orthodontics. 2007;29(6):627-31.

28. Forster CM, Sunga E, Chung CH. Relationship between dental arch width and vertical facial morphology in untreated adults. The European Journal of Orthodontics. 2008;30(3):288-94.

29. Bishara SE, Ortho D, Jakobsen JR, Treder J, Nowak A. Arch width changes from 6 weeks to 45 years of age. American Journal of Orthodontics and Dentofacial Orthopedics. 1997;111(4):401-9.

30. Moyers RE, Van der Linden FPGM, Riolo ML, McNamara JA. Standards of human occlusal development. Monograph 5. Craniofacial Growth Series. Ann Arbor: Center for Human Growth and Development; University of Michigan; 1976. 